\title{
Promoting Students' Soft Skills in a Telecommunication Engineering Course with an Elevator Pitch Activity
}

\author{
https://doi.org/10.3991/ijet.v16i24.26767 \\ Miguel Ferrando-Rocher $\left({ }^{\bowtie}\right)$, Stephan Marini \\ Universidad de Alicante, San Vicente del Raspeig, Spain \\ miguel.ferrando@ua.es
}

\begin{abstract}
An elevator pitch is a short summary used to quickly and simply define a process, product, service, organization, or event and its value proposition. The name comes from the idea that it should be possible to deliver the summary within the time span of an elevator ride, so anywhere between 30 seconds and 2 minutes, which means the key points need to get across quickly. In this particular educational context, technical students have been encouraged to defend, under the typical rules of the elevator pitch, the knowledge acquired during the semester in a specific subject. This contribution focuses on the classroom experience and how the transversality of the activity can help students to strive and think in a different way than they are used to in the classroom of a technical career.
\end{abstract}

Keywords-education, learning environments, partnership, collaboration, evaluation

\section{Introduction}

Soft skills are the additional or supplementary skills needed by engineers necessary in today's global scenario. Strong communication and interpersonal skills are essential to enhance employability. Soft skills provide students with a solid conceptual and practical background for building, managing and developing teams. They play an important role in overall personality development, thus enhancing the student's career perspectives. Some of the soft skills necessary for success are quality leadership, teambuilding, conflict management skills, interpersonal skills, self-management skills, empathy, negotiation, personal effectiveness, goal orientation, flexibility, problem-solving skills or written and oral communication skills. It is on this last skill that the present study is focused, since it is considered a crucial one within the transversal competencies that an engineer must acquire, and which is not always promoted as much as it would be desirable in the curricula. In addition, the development of speaking skills in today's professional context is increasingly critical for any student in higher education, both at the undergraduate and graduate within and beyond the university stage.

Many universities are promoting skills linked to entrepreneurship, given the enormous change entrepreneurship that is taking place in the labor in the workplace at all levels [1], [2]. In this context, the ability to convey ideas in an agile, clear and simple 
way, in a convincing and even attractive manner, has become a key element [3], [4] in the set of transversal competencies that aim to make the student more proactive [5]. Thus, as an activity to develop this transversal competency as part of a flipped classroom system is being increasingly and more and more extensively proposed [6]-[11]. Some authors have approached it by using an activity known as "elevator pitch" with really satisfactory results [12]-[14].

The elevator pitch is an educational experience that reproduces the situation of a person who has the duration of an elevator ride to present an idea, a product, a service or a business to a potential investor. In this scenario, the hypothetical client is the rest of the class to whom the "product" will be presented, which in reality is the knowledge acquired during the semester. This elevator pitch approach may not be relevant in the first instance to an engineering student. Here it is not so important to sell an idea to an investor but to be able to communicate effectively and in a very short space of time a certain topic. The activity is not finalistic and is not intended to evaluate the students from a numerical point of view, but rather to encourage their orality and their ability to reflect on the knowledge they possess and to know how to transmit it effectively.

The activity described here was carried out during the 2020-2021 academic year in the Signals and Systems course of the Telecommunications Engineering degree (Image and Sound specialty) at the University of Alicante (UA), in Spain.

\section{Methodology}

The methodology was based on three main blocks: 1) preparation, 2) challenge and 3) feedback. It is described below:

1. First, the activity is explained and put into context. There are countless resources that make it easy to illustrate what an elevator pitch is. However, this activity has a particular structure since it is far from trying to sell a business idea, but rather to transmit in a concrete way some acquired knowledge and to know how to defend it in front of classmates. Thus, students were encouraged to make a draft of their presentation, following the outline in Figure 1. In this way they could cooperatively check whether the content and length of the text to be defended was appropriate.

2. Pitch Challenge: The term 'challenge' is a term used in social networks to define a viral trend in which the rest of the people are invited to perform a challenge, to do something, either for a charitable cause or just for fun. By integrating this trend into the activity, we propose to turn the elevator pitch activity into a challenge, which motivates students to a healthy competitiveness. Thus, in the challenge, each of the students must present their 2-minute pitch to the rest of the class, in which they must specify what they have learned during the course, why they believe it is valuable and what it will be useful for them in the future. Of course, this activity was carried out in the last week of the course, so that the students had a global vision of the course to defend in their pitch.

3. Feedback: After the individual presentation, the activity does not end, but after the different pitches there is a round of discussion and feedback from the rest of the students. Once each round is finished, a collective evaluation of the strengths and 
areas of improvement of each presentation is made, so that the presentation becomes an excellent tool for improving the skill.

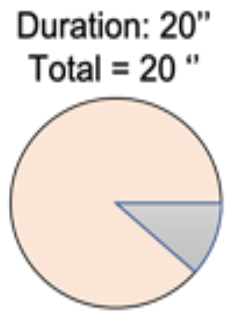

Introduction

Short personal presentation

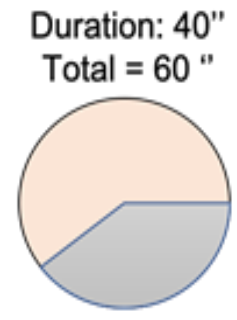

Key 1

What key concepts have you learned in this course?

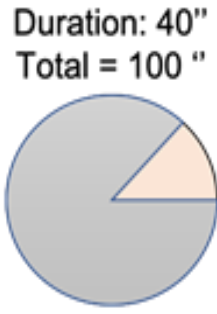

Key 2

Why do you think these concepts are important in your career?

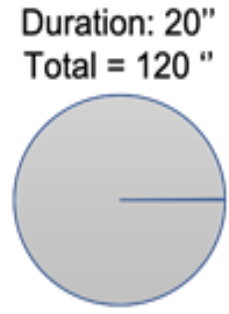

Conclusion

Closing of the presentation. Preferably using non-conventional formulas.

Fig. 1. Flow chart of the proposed elevator pitch

\section{Results}

The activity was carried out in the high-performance group in the Signals and Systems course of the second year of the telecommunication engineering degree at the University of Alicante (UA). The total number of students enrolled in this group in the academic year 2020-2021 was 14. The students participating in the experience were 11 . The activity was carried out in week 15 of the course (at the end of the term) and had a total duration of 3 hours. One hour of preparation, one hour of realization and one hour of feedback. At the end of the experience, the students freely expressed their opinions, among which the following stand out:

- First subject in which they carried out this activity.

- Useful and motivating activity.

- An activity that encourages reflection on the contents.

Finally, it should be noted that this experience is framed within the Basic Transversal Competences of the subject and verified by the National Agency for Quality Assessment and Accreditation (Agencia Nacional de Evaluación de la Calidad y Acreditación - ANECA). The objective of the competency CT2 is that students know how to apply their knowledge to their work or vocation in a professional manner and possess the skills that are usually demonstrated through the development and defense of arguments. 


\section{Challenges for the activity's future in the new educational context}

The proposed activity seems that it may only make sense from a face-to-face activity point of view but recent events make us reflect on the future of this activity. During the current pandemic all universities worldwide have had to make an abrupt transition to distance learning and teaching modalities. Many are still wondering about the effectiveness and level of commitment to this type of learning, but it is clear that it has been the lifeline to avoid the loss of one or two academic years. Many teachers were not prepared for this abrupt change, but the ability to adapt has been very high.

During this period, the UA has carried out a major project to equip more than 300 classrooms and halls for the installation of video-monitoring systems. This system allows the automatic recording of all classes, using $4 \mathrm{~K}$ video cameras, high quality microphones and projected screen capture systems. The video cameras are sent over the network as streaming to the central server. The audio is adjusted with a small mixer and digitized. The projected video, in VGA, DVI or HDMI format, is also captured locally with a mini PC. All signals are concentrated in a Gigabit switch and sent to the central servers, where they are processed. This high-quality infrastructure in all classrooms will enable new hybrid teaching modes.

In addition, recent experience shows that there is a decrease in attendance in faceto-face classes. This should be corrected by new initiatives, as the one here presented, that encourage interaction in the classroom, such as problem solving, projects, along with a greater emphasis on continuous assessment. With regard to attendance for conventional and necessary activities, such as theory and blackboard lessons, the recorded video notes are available on a repository for later use. Students can watch the video repeatedly to review some important concepts. This tool is also a great help for students with attendance waivers or those who have not been able to attend class for justified reasons. The student can choose a view of the projection, the classroom with the blackboard or a composite of both. Figure 2 shows an example of these video notes, recorded during the 2020-2021 academic year.

Thus, although the pitch challenge is a particular activity that is confined to a classroom experience, it fits perfectly with the new paradigm facing today's university. While theory classes are essential for student training, certain activities such as group work, collaborative work, or oral presentations, foster the student's interrelation and transversal competencies, so it is necessary to promote them with face-to-face activities, as far as possible. 


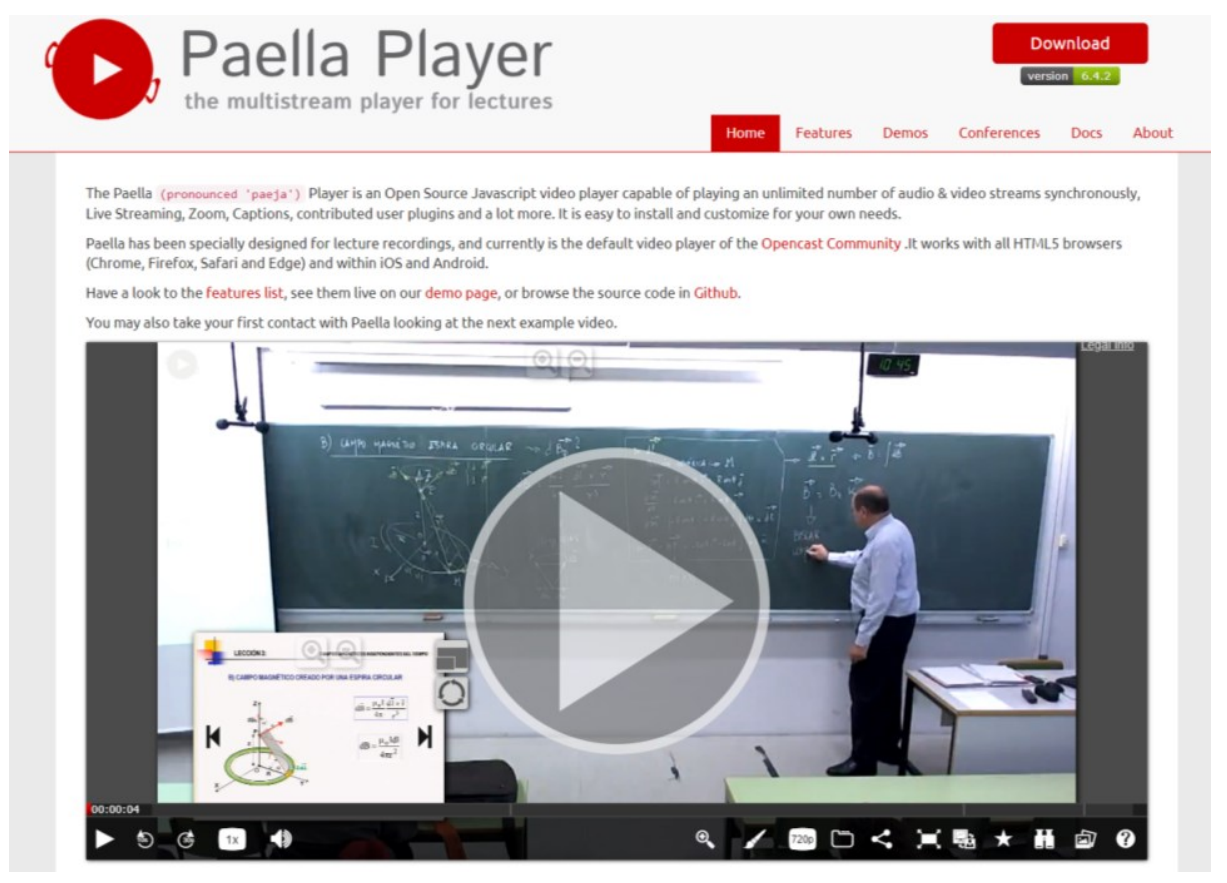

Fig. 2. Application of video notes

\section{Conclusion and discussion}

An elevator pitch has been proposed to stimulate oral communication skills in a 2 nd year course of the telecommunication engineering degree at the UA. The activity, under the name of "Pitch Challenge" makes use of the well-known elevator pitch technique used mainly in marketing. It is expected that the Pitch Challenge can be consolidated within the study guide of the subject in future years, in order to assess whether it has a positive performance, a good acceptance and a real and beneficial impact on students.

\section{Acknowledgment}

This work has been supported by a grant from the "Programa de Redes-I3CE" for research in university teaching of the Instituto de Ciencias de la Educación (ICE) of the University of Alicante (2020-21); ref: 5039: "Metodologías de trabajo colaborativo en Señales y Sistemas del Grado en Ingeniería en Sonido e Imagen en Telecomunicación."

\section{$7 \quad$ References}

[1] Klofsten, M. (2000). Training entrepreneurship at universities: a Swedish case. Journal of European Industrial Training, 24 (6): https://doi.org/10.1108/03090590010373325 
Short Paper-Promoting Students' Soft Skills in a Telecommunication Engineering Course with an...

[2] Schipper, M., \& van der Stappen, E. (2018, April). Motivation and attitude of computer engineering students toward soft skills. In 2018 IEEE global engineering education conference (EDUCON), Santa Cruz de Tenerife, Spain. IEEE. https://doi.org/10.1109/ educon.2018.8363231

[3] Pereira, O. P., \& Costa, C. A. A. T. (2017). The importance of soft skills in the university academic curriculum: The perceptions of the students in the new society of knowledge. International journal of Business and Social Research, 7 (6): 1-12. https://doi.org/10.18533/ ijbsr.v7i6.1052

[4] Wee, K. N. L. (2004). A problem-based learning approach in entrepreneurship education: promoting authentic entrepreneurial learning. International Journal of Technology Management, 28(7-8): 685-701. https://doi.org/10.1504/iitm.2004.005777

[5] San Tan, S., \& Ng, C. F. (2006). A problem-based learning approach to entrepreneurship education. Education+ Training, 48 (6): 416-428 https://doi.org/10.1108/004009106106 $\underline{92606}$

[6] Aprianto, E., \& Purwati, O. (2020). Multimedia-Assisted Learning in a Flipped Classroom: A Case Study of Autonomous Learning on EFL University Students. International Journal of Emerging Technologies in Learning (iJET), 15(24): 114-127. https://doi.org/10.3991/ijet. $\underline{\mathrm{v} 15 \mathrm{i} 24.14017}$

[7] Zarouk, M., Olivera, E., Peres, P., \& Khaldi, M. (2020). The Impact of Flipped ProjectBased Learning on Self-Regulation in Higher Education. International Journal of Emerging Technologies in Learning (iJET), 15(17): 127-147. https://doi.org/10.3991/ijet. v15i17.14135

[8] Shaykina, O. I., \& Minin, M. G. (2018). Adaptive Internet Technology as a Tool for Flipping the Classroom to Develop Communicative Foreign Language Skills. International Journal of Emerging Technologies in Learning, 13(7): 243-249. https://doi.org/10.3991/ ijet.v13i07.8092

[9] Wali, A., \& Popal, A. (2020). The Emerging Issues and Impacts of Technology in Classroom Learning. International Journal of Emerging Technologies in Learning (iJET), 15(15): 237 245. https://doi.org/10.3991/ijet.v15i15.14175

[10] Liu, L. (2019). Face-to-face Teaching in the Flipped Classroom Supported by Visualization Tools--Taking the course of" Architectural Design of Housing" as an Example. International Journal of Emerging Technologies in Learning, 14(3): 220-233. https://doi.org/10.3991/ijet. $\underline{\mathrm{v} 14 \mathrm{i} 03.10106}$

[11] Li, J., Zhang, X., \& Hu, Z. (2018). The Design and Application of Flip Classroom Teaching Based on Computer Technology. International Journal of Emerging Technologies in Learning, 13(10): 95-107. https://doi.org/10.3991/ijet.v13i10.9453

[12] Lacka-Badura, J. (2020). Personal branding in an elevator: Developing job search pitch skills in tertiary level Business English pedagogy. Language Learning in Higher Education, 10(1): 207-215. https://doi.org/10.1515/cercles-2020-2007

[13] Miranda Benavides, K., Prendas Aguilar, G., \& Miranda Benavides, Y. (2020). Utilización de estrategias para el desarrollo de competencias en el ámbito universitario: elevator pitch, debates y talleres. VII Iberoamerican Conference on Educational Innovation in the field of TIC and TAC, pp.299-303. ISBN 978-84-09-22254-4.

[14] Romero, E., Artal, J. S., Artacho, J. M., \& García Aranda, J. R. (2017). Aprendizaje invertido con Elevator Pitch y Pecha Kucha [Flipped Learning with Elevator Pitch and Pecha Kucha]. IV International Congress on Learning, Innovation and Competitiveness, Zaragoza, Spain. https://doi.org/10.26754/cinaic.2017.000001 139 


\section{Authors}

Miguel Ferrando-Rocher received the M.Sc. and Ph.D. degrees in telecommunication engineering from the Universitat Politecnica de Valéncia (UPV), Valéncia, Spain, in 2012 and 2018, respectively. In 2012, he joined the Complex Radiation Systems Team, Institute of Electronics and Telecommunications Rennes, France, as a Researcher, where he was involved in reflectarray antennas for satellite applications in collaboration with Thales Alenia Space, Paris, France. Since 2013, he has been with the Antennas and Propagation Laboratory of UPV. In 2016, he joined the Chalmers University of Technology, Gothenburg, Sweden, as a Guest Researcher. Since September 2019, he is an Assistant Professor with the Department of Physics, Systems Engineering and Signal Theory, University of Alicante. Dr. Ferrando-Rocher was a recipient of the Extraordinary Prize for Doctoral Theses from the Polytechnic University of Valencia, in 2020, the AIRBUS Defence and Space Award, in 2019, and the URSI Conference Best Student Paper Award, in 2017 and finalist in 2019. He received the Erasmus Grant to study with Ghent University, Ghent, Belgium, in 2010.

Stephan Marini received the Laurea degree in electronics engineering from the University of Perugia, Italy, in 2001, and the Ph.D. degree in telecommunications from the Universidad Politécnica de Valencia, Spain, in 2005. In June 2001 he joined the "Departamento de Comunicaciones", Universidad Politécnica de Valencia, in the frame of an European Union Project. Since 2005 he has been an Assistant Professor in the University of Alicante, Spain, where he became Associate Professor in 2012. Since October 2015 he is the director of the Microwave and Applied Computational Electromagnetics Group (GMECA, http://web.ua.es/es/gmeca/) of the Instituto Universitario de Física Aplicada a las Ciencias y Tecnologías. He currently holds the position of Secretary of the Polytechnic School of the University of Alicante.

Article submitted 2021-09-08. Resubmitted 2021-11-05. Final acceptance 2021-11-05. Final version published as submitted by the authors. 




iJET - Vol. 16, No. 24, 2021

\section{Imprint}

iJET - International Journal of Emerging Technologies in Learning http://www.i-jet.org

\section{Editor-in-Chief}

Dominik May, University of Georgia, United States

\section{Executive Editor}

Michael E. Auer, CTI Frankfurt/Main, Vienna, New York, Bengaluru

\section{Associate Editors-in-Chief}

Martin Ebner, TU Graz, Austria

Mohammad Khalil, University of Bergen, Norway

\section{Associate Editors}

Neelakshi Chandrasena Premawardhena, University of Kelaniya, Sri Lanka

Christina Merl, Vienna, Austria

Jalal Nouri, Stockholm University, Sweden

Stamatis Papadakis, University of Crete, Greece

Valerie Varney, RWTH Aachen University, Germany

\section{Technical Editor}

Sebastian Schreiter, Lagorce, France

\section{Editorial Board}

A. Y. Al-Zoubi, Princess Sumaya University for Technology Amman, Jordan Gerald Friedland, International Computer Science Institute, Berkeley (CA), USA

Andreas Holzinger, Medical University Graz, Austria

Dr. George S. Ioannidis, University of Patras, Greece

Andreja Istenic Starcic, Slovenia University of North Texas, US

Barbara Kerr, Concordia University Montreal, Canada

Lars Knipping, TU Berlin, Germany

Massimo Marchiori, World Wide Web Consortium (W3C) at MIT

Andreas Pester, Carinthia University of Applied Sciences, Austria

Rob Reilly, University of Memphis and MIT Media Lab, USA

Cornel Samoila, Transilvania University Brasov, Romania

Mario Žagar, University of Zagreb, Croatia

\section{Indexing}

International Journal of Emerging Technologies in Learning is indexed in Clarivate Analytics ESCl, Elsevier Scopus, El Compendex, DBLP, Ulrich, EBSCO, INSPEC, LearnTechLib, and Google Scholar.

\section{Publication Frequency}

Bi-Monthly

\section{ISSN}

1863-0383

\section{Publisher}

International Association of Online Engineering (IAOE)

Kirchengasse 10/200

A-1070 Vienna

Austria 